\title{
First observations of SN 1604 (Kepler's supernova)
}

\author{
Alessandro de Angelis and Selenia Broccio \\ Dipartimento di Fisica e Astronomia “Galileo Galilei” dell’Università di Padova, Padova, Italy
}

October 20, 2021

\begin{abstract}
A supernova close enough to the Earth is a spectacular event: it can appear as a "new star" as luminous as Venus, or even more, visible for several days. The rate of Galactic supernovae is expected to be of about one in 30 years, with a fraction visible at naked eye; however in all the history of human civilization only seven supernovae in the Milky Way have been reported, the last two (1572 and 1604) during Galilei's life.

The supernova of 1604, today called Kepler's Supernova, was observed by Galilei, Kepler and other astronomers in Europe, Korea, and China. Like the supernova SN1572, today called Tycho's supernova, it has been the subject of extensive studies, and inspired observational measurements and philosophical considerations on the nature of the heavens.

The remnant of SN1604 has been indicated by recent X- and gamma-ray data to be a likely site of cosmic ray acceleration. The first recorded data of optical observations, together with new data, can still tell us a lot about the early evolution of this supernova.

Keywords: Supernova remnants; Stellar evolution; High-energy astrophysics
\end{abstract}

\section{Introduction}

Stars and binary stellar systems massive enough end their lives in collapses releasing a large amount of energy; these phenomena are called "supernovae". A supernova close enough to the Earth is a spectacular event: it can appear as a "new star" as luminous as Venus, or even more, visible for several days. The rate of Galactic supernovae is expected to be of about one in 30 years, with a fraction visible at naked eye; however in all the history of human civilization only seven supernovae in the Milky Way have been reported, the last two (1572 and 1604) during Galilei's life [6].

The 1604 Supernova (SN 1604, also known today as Kepler's supernova) has been the last of the seven Galactic supernovae tracked in history of humanity, the previous four having been recorded in 185 A.D., 393, 1006, 1054 (the remnant of which is called the Crab nebula), 1181, 1572 (today called Tycho's supernova [4]).

In October 1604, when the supernova appeared in the sky, Galileo Galilei (15 February 1564 - 8 Jenuary 1642) was teaching Mathematics and Physics at the University of Padua, and for the two-year period 16041605 he had chosen the motion of the planets (the Theoretics of the Planets) as the subject of his lectures. Galilei was therefore the reference figure to whom were addressed all the doubts and questions that such an apparition brought with it $[8,18]$.

That very bright and pulsating sphere had generated wonder, but also terror and such curiosity that Galilei was officially asked to make the picture of the situation by exposing in some public lectures his point of view, so as to answer the many questions that raged both among the ranks of the academic community and among ordinary people. Towards the end of November/beginning of December 1604, Galilei gave three public lectures, of which only a few fragments of his preparatory notes remain today [8].

Although he was asked several times to publish what he had exhibited in those three public lectures, Galilei continued to postpone, waiting to write a larger work, because he felt that his lessons were not innovative and not worthy of being read or published, as they focused almost exclusively on proving, through the parallax method, that the "new star" was located beyond the Moon. Galilei had made such detailed explanations for the benefit of the audience, but talking about parallax meant dealing with easy elementary geometry exercises which, for Galilei, could not be the subject of a publication.

In Letter n. 113 ([9] in [1]), dated January 1605, Galilei wrote to the Nobleman Onofrio Castelli that he thought he had reached a conclusion without contradictions, something more than mere speculation in a complete description of the new star: its position, motion, composition and creation. He had therefore decided to present his thought, even though he was well aware of the risk of censorship that he would have faced. For when, in his public lectures, he had stated that there was no doubt that the Star lay far beyond 
the Moon, he had incurred the wrath of the Aristotelians. He therefore decided to be extremely careful in examining all possible hypotheses, and so he decided to wait a little longer before publishing $[8,7]$.

Compared to that of 1572, the stella nova on which Galilei gave his three public lectures caused much greater excitement, since its appearance was concurrent with the Conjunction of Mars with Jupiter, that happened just ten months after another very importat astronomical event : the conjunction between Jupiter itself and Saturn.

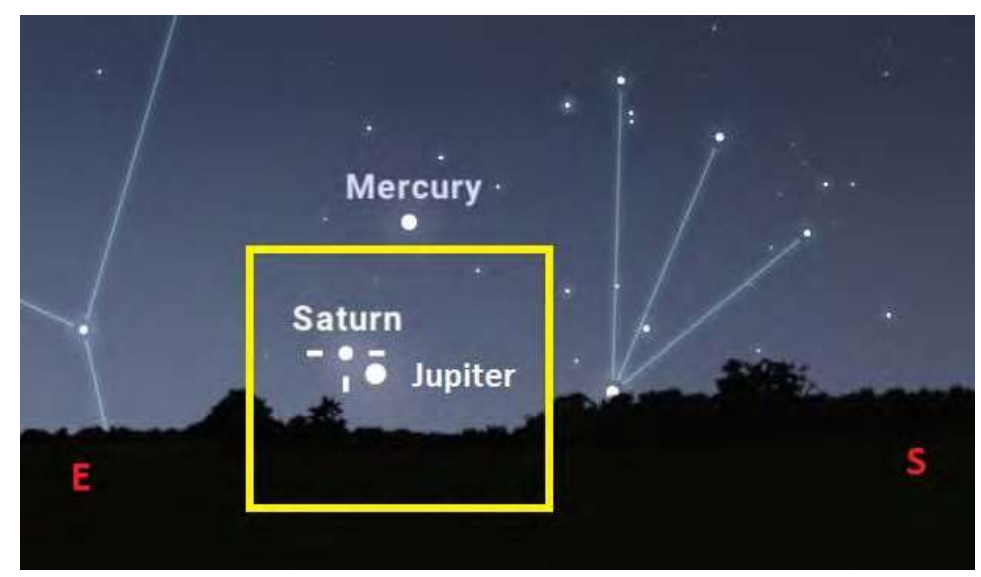

Figure 1: Conjunction between Jupiter and Saturn, ES, 17.12.1603, 06:30 a.m.

Astrologers had predicted great events as a result of the Conjunction of Jupiter and Saturn, especially since it would take place in a fire sign (Sagittarius), and this would have meant the beginning of a new cycle for the Fiery Trigon, which used to be the bearer of wonderful events. The anticipation for this new beginning had grown more and more over the years.

The second expected event was Mars which was to overtake Saturn and go in conjunction with Jupiter, as it has been predicted by the astronomical tables, and it was expected to take place on October 8, 1604 . The event event had an unexpected guest in attendance.

\section{Galilei, Kepler and the Stella Nova}

On October 9, at sunset, Ilario Altobelli saw the new star for the first time; he was the first known observer to report on it. In the letters he wrote to Galilei between November 1604 and January 1605 (See Appendix), Altobelli was extremely generous with observational details, and repeated several times that the star had not appeared until 9 October. This extreme precision on the date was mainly due to the necessity of removing any possible credibility from some rumours that wanted its first appearance on the 27 th of September.

Altobelli was confident that up to and including 8 October, there were only Mars, Jupiter and Saturn in the sky, which were slowly, night after night, reaching the expected configuration. The appearance of the stella nova left Altobelli incredulous in his own eyes, but having spent every evening and night looking at that same part of the sky recording the evolution of what he was observing, he had no doubts: the star had appeared suddenly, on 9 October, while the conjunction of Jupiter and Mars was taking place.

Altobelli described it as similar to the stars of the eighth sphere, i.e. of a non-changing and glittering colour. He undoubtedly placed the position of the Star among the fixed stars, and described its colour as a "half-yellow, half-green orange, or even a mixture of yellow and green".

The day Altobelli saw the star for the first time, it seemed to him to be the same size as Jupiter, but then, because of the bad weather, he was unable to see anything more until tht 15 th of October, when the sky finally became clear and the new star appeared, as he reported, a little larger than he remembered. Over the next few days he seemed to see it decrease in size very slightly, but it was still comparable to Jupiter.

Altobelli expressed a first hypothesis on the composition of the star, starting from the fact that having appeared in a sign of fire, close to the Ecliptic and not far from the Sun, it could only have had a nature of "burning flame". He also excluded that it could be some kind of "globe suspended by a hypothetical balance between air of different densities", since air was considered to be liquid and mobile in nature, whereas the star showed no motion whatsoever.

The "stella nova" was observed in Padua on 10 October 1604 by Galilei's students; hi was warned immediately (indirectly), but due to cloudy weather he could not see it until a few days later. 


\subsection{Galilei's conjectures}

In the remaining fragments of his preparatory notes to the lectures he later delivered in public, Galilei wrote of a light that appeared the 10th of October at the sunset, stating that during the conjunction of Mars and Jupiter in the presence of Saturn, which occurred on October 9 at about 5 in the morning, "we have not seen in that area any other star than the three mentioned".

It is necessary to point out that, as Galilei himself reported, he saw the Star for the first time with his very own eyes on October 28. The data collected during the very first observations had therefore not been made by him, but since he was the person called upon to put together the pieces of an extremely complex puzzle, he did exactly what he was asked to do: put the pieces together to provide an explanation as complete as possible.

To those who later criticised his absence during those first observations, as if to emphasise a lack of complete mastery of the subject, Galilei sarcastically replied that "it seems that there is nothing more serious for those in charge of science than not to have been the first among all to have seen the Star, almost as if there was an imperative obligation to spend every moment of one's life with one's eyes on the sky, waiting for some new star to appear."

Galilei reported of a light that was initially very faint and then, in a few days, became so intense that it "outshone all the stars, both fixed and mobile, with the exception of Venus alone, [...] so sparkling that it almost seemed to vibrate, and with a light colour similar to both the golden of Jupiter and the reddish of Mars".

Galilei did not rule out that the creation of the star might actually have taken place before 10 October, but that due to the initially weak light, the nova might not have been visible because it was hidden by the light of Jupiter and Mars in conjunction.

Galilei also recognised how alluring was the idea that "such light was generated by the conjunction of Jupiter and Mars; and this, moreover, above all, because it appears to have been generated almost in the same place and at the same time in the conjunction of the said planets".

In some notes written after the public lectures, Galilei speculated on the origin, cause and composition of the nova, and one of his very first hypotheses was that the star could not have originated from an explosion. Daily evidence led him to conclude that objects that ignite rapidly also tend to burn out at the same rate, whereas the nova had remained visible and 'lit up' until February 1606, so such a flame could not have had an explosive cause.

\subsection{Controversy with the Peripatetics and with Capra}

The presence of a new celestial body located in the eigth sphere of the fixed stars greatly stirred the followers of the Aristotelian school, who professed a simple, perfect, ingenious and incorruptible sky [10], devoid of change. The evidence of the facts, however, was another, and so they sought interpretations and explanations that could make compatible that novelty of the sky with a model that denied the very possibility of novelty itself.

Some among them argued that, since the nova was a new body, it could only be within the lunar sphere, that is, between the Earth and the Moon, where, according to the Aristotelian dogma, matter was allowed to modify itself. But to support this hypothesis, they necessarily had to deny the validity of the parallax method, which showed instead that the star was far beyond the Moon, just as Galilei had explained during his public lectures.

Others denied that it was 'new', and argued rather that it had always been there, among the fixed stars, but not visible; still others ruled that its creation was a divine decision, and therefore there was no reason to investigate further.

\subsubsection{Antonio Lorenzini's Discorso intorno alla nuova stella and Galilei's reply in Dialogo in perpuosito de la nuova stella}

A months after Galilei's lectures, on 15 January 1605, the otherwise unknown Antonio Lorenzini ${ }^{1}$ da Montepulciano published in Padua a booklet [15] entitled Discorso intorno alla nuova stella. Faced with the undeniable evidence of the star's lack of parallax, and in order to justify Aristotle's concept of the immutability of the sky, Lorenzini came up with a completely new set of geometric rules, which were so complicated and considered so confusing that no academic took them into consideration.

Lorenzini attacked the mathematicians and astronomers who had placed the star outside the elementary sphere, and therefore, more specifically, his work was a criticism addressed to Galilei.

\footnotetext{
${ }^{1}$ Behind the name of Lorenzini, it is not difficult to see the inspiration of Cesare Cremonini (1550-1631), professor of natural philosophy in Padua and both a rival and a friend of his colleague Galileo.
} 
Lorenzini concluded his work by making astrological predictions and forecasts, as he argued that the new star would influence the seasons, the harvests and the physical and moral health of all mankind.

Galilei's response was quite particular: on 28 February 1605 the Dialogo in perpuosito de la stella nuova (Dialog about the new star) was published in Padua, a pseudonimous booklet in Paduan dialect written by Galilei and the benedictine monk Girolamo Spinelli [11]. That little book was an explicit mockery of what Lorenzini had published, and since it slandered the entire Aristotelian dogma, the two authors preferred to hide their names under the pseudonym of Cecco Ronchitti da Bruzene. Cecco da Ronchitti (a small farmer village near Padua), an unknown self-declared peasant, gave in the book many indications that the real author was the professor of Astronomy in Padua.

The Dialogo takes place between two farmers, Matteo and Natale, confronting each other after Natale has read Lorenzini's book and tells Matteo about its contents. The booklet analyzed point by point the contradictions and distortions expressed by Lorenzini in his Discorso. So, Galilei did not react personally to what Lorenzini had written, but he did so through the pen of Spinelli and the dialectal, clever and forthright voices of the two peasants.

\subsubsection{Baldassarre Capra's Astronomical consideration about the new star and charges against Galilei; Galilei's reply}

On February 16, 1605 was published in Padua the Consideratione astronomica sopra la nova et portentosa stella che nell'anno 1604 a di 10 ottobre apparve. Con un giudicio dei suoi significati (Astronomical consideration about the new and prodigious star appeared on October 10, 1604, with a judgement on its meaning), written by the Italian astronomer and mathematician Baldassarre Capra [5].

About the position of the star, Capra had no doubts: in no way it could be below the Moon. But, while repeating what Galilei had already shown during his public lectures (that Capra had attended) when he had given examples to explain how the absence of parallax was indicative of an enormous distance, Capra attributed to the star an extremely small parallax, so small that it could not be detected, but not zero.

Capra wondered what could have caused the star, but admitted that he was unable to explain any of it. He was aware that the Aristotelian hypotheses were not suitable and that there was a need to find other explanations, but, again, he confessed that he was not capable of doing so.

He also speculated about the meaning of the star, expecially in relation to the star that had appeared in 1572 in Cassiopeia, because he noticed that the two stars had appeared exactly 32 years apart - a number of years equal to the age of Christ. This led him to consider that both stars were carriers of great and wonderful events, "like the comet seen by the Magi in conjunction with the birth of Christ, which foretold the destruction of Judea and the conversion to the true faith".

But the controversy between Capra and Galilei began with three main accusations Capra made against the Padua professor:

1. He accused Galilei of being too imprecise with regard to the accurate date of the star's appearance.

In his lectures, Galilei had reported that the star had appeared between the 8th and 10th of October ${ }^{2}$, while Capra was sure that the correct date was 10 . He was also sure that Galilei knew this, since Capra himself had arranged for the news to reach him a moment after seeing the star for the first time.

2. Therefore, Capra interpreted that non-precision on the date as a clear intention from Galilei to take away his recognition for having first seen the nova throughout Padua. Capra knew that Galilei had not observed the nova until 28 October, and therefore accused him of claiming merits that could not be his.

3. Capra asserted that Galilei, on his first personal day of observation (28.10.1604), had completely misjudged the area of the sky in which the nova was located. According to Capra, Galilei had placed the nova on the straight line joining the Swan's Tail to the Boreal Crown (Fig. 2, green line), when at the time the star was rather on the straight line joining Mars and Jupiter (Fig. 2, orange line).

In the beginning Galilei did not reply publicly. He just annotated his personal copy of Capra's booklet with harsh and often vulgar comments.

Galilei's replied to the accusations Capra had made only a couple of years later [12], when Capra accused him again, and this time the accusation concerned the theft of the invention of the geometric compass. Galilei then decided to stand up for his own good name (and for the economic revenue granted him by the compass, which was comparable to his salary), and wrote the booklet Difesa contro alle calunnie ed

${ }^{2}$ in the preparatory notes Galilei wrote "10 October", but during the public exhibition he did not exclude the possibility that the nova might already have been seen in the days immediately preceding the 10th of October. 


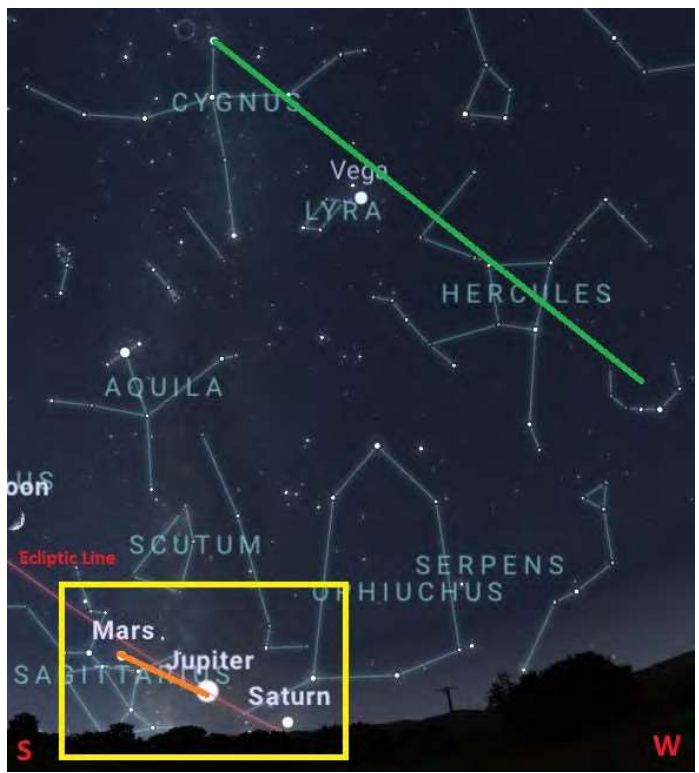

Figure 2: Third charge of Capra against Galilei: SW, 28.10.1604, 06:30 a.m.

imposture di Baldassarre Capra (Defense agaist the calumnies and pretences of Baldessar Capra), in which he also spoke about Capra's three accusations about the stella nova.

1. With regard to the alleged inaccuracy concerning the true date of appearance of the star, Galilei replied that saying "approximately" during his lectures was a matter of caution, since others might have seen the star in the days immediately before.

2. Galilei pointed out that during the first of the three public lectures, he had explicitly stated with words of praise that it was Capra himself who had observed the star first in Padua. Galilei also dwelled on the irrelevance of the very concept of primacy when it comes to discoveries, as he believed that being present during an event was just a fortuitous event, which had nothing to do with the observer's skills.

3. Finally, regarding the accusation of having observed a completely wrong area of the sky, Galilei replied that he had never spoken of Swan's Tail, but rather of Bear's Tail, thus accusing Capra not only of lack of attention during lessons but also of a poor knowledge of the Latin language.

\section{Kepler and the observations in the rest of Europe}

Johannes Kepler at the time of the appearance of nova was the imperial Mathematician and Astronomer of Rudolf II of Augsburg, Holy Roman Emperor. He was correspondant of Galileo, and the letters between the two scientists indicate reciprocal confidence and esteem.

Kepler studied the stella nova for over two years, at the end of which he published in 1606 the De Stella Nova in Pede Serpentarii (The new star in Ophiucus' foot) [14]. This comprehensive overview is the most complete archive of visual information about the new star, as it contains a huge amount of observational data, acquired during the 18 months that the star remained visible, provided by astronomers from all over Europe. In addition to the descriptive part, which includes very precise data about the position of the star with respect to the other fixed stars, as well as its changes in colour and brightness, there are also numerous chapters in which Kepler could not avoid to face, due to his official role as Imperial Astronomer, all those arguments that were very much in vogue at the time, concerning the examination of the possible meanings for the appearance of the stella nova, which was considered to be bearer of omens.

Such a treatise required much caution, and it was Kepler himself, addressing directly Emperor Rudolf II, to whom he dedicated the entire work, who explained the two main reasons that led him to postpone its publication several times: the first was that he had decided to wait until the stella nova was no longer visible, so to be able to have the full picture, and the second was the extreme difficulty in which he found himself dealing with the chapters relating to the meaning of the star. And it is precisely the way in which Kepler wrote these chapters that shows how much he rejected the idea that there could be a definitive answer in fields without mathematical foundations, because too much space is left for interpretation. 
The numerical data of positions and what was reported as morphological characteristics of the nova were not interpretable: these data could maybe reflect measurement errors due to instrument or to the eyesight of the observer, but no opinion was required. On the other hand, going into a field that does not speak the language of numbers and wants however to investigate the nature of the heavens, would have required a hubris that Kepler repeatedly stated did not want to make his own.

What he wrote on this subject was a stream of considerations in which he analysed the opinions that were most prevalent at the time, such as, for example, the conflict between the currents of thought that attributed every event to chance and those who instead obsessively sought a divine meaning with which make predictions of future events.

To the question "what is the meaning of the nova?" Kepler did not give an answer, nor did he ever make any assumptions, because, as he said, doing so would have meant arrogating to oneself knowledges far beyond what humans can have. But mainly because trying to find meaning in the appearance of a new body in the sky had nothing to do with astronomical studies, which were instead what Kepler wanted to concentrate his energies on.

\subsection{The Fiery Trigon}

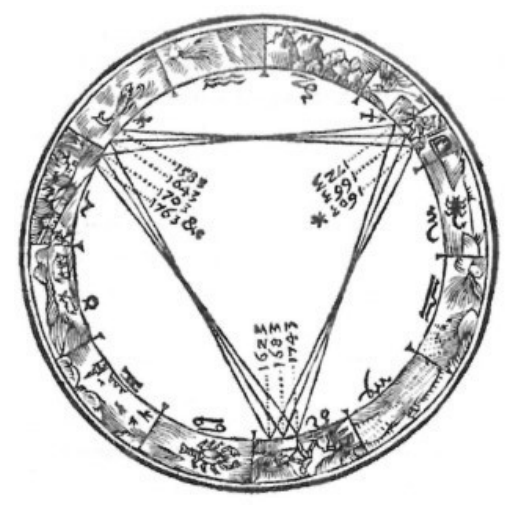

Figure 3: Entering the Fiery Trigon. De Stella Nova, Chapter VII.

Explaining what the Fiery Trigon was and giving a basic information of the astrological traditions and beliefs of the time, was essential for Kepler in order to understand the reason for so much excitement around the new star: "so that future readers cannot complain that they are left without help on the question" [14].

One of the most powerful geometric figures in astrology is the triangle, closely linked to the zodiac: astrologers divide the circle of the zodiac into twelve equispaced parts whose names, placed clockwise, are Aries, Taurus, Gemini, Cancer, Leo, Virgo, Libra, Scorpio, Sagittarius, Capricorn, Aquarius, Pisces. These signs are grouped in four triads, thus forming the four elementary triangles: Fiery Trigon (Aries, Leo, Sagittarius), Earthy Trigon (Taurus, Virgo, Capricorn), Airy Trigon (Gemini, Libra, Aquarius), Watery Trigon (Cancer, Scorpio, Pisces).

The division into four groups was also due to the characteristics identified in the sensations associated with the four seasons: heat, cold, wetness, dryness. Each of these prevails in a particular one of the elements, respectively heat in fire, cold in water, humidity in air, and dryness in earth.

The question that arose was therefore what considerations must have been made in order to associate each sign with a particular one of the four Trigons, so as to identify it with the properties of the associated element (fire, water, air, earth), especially since astrologers made predictions and horoscopes on the basis of the belief that the names given to the stars and constellations contained some deep meaning that had to be interpreted according to the Trigon to which they belonged, making certain stars more powerful than others.

Kepler recognized the historical and cultural value of the names given to the stars and constellations, but he firmly denied that such names could conceal mystical meanings and secrets, especially because the meaning to give to the chosen name depended on the arbitrariness of who had chosen it. 


\subsection{The conjunction of Saturn and Jupiter}

This conjunction is visible from the Earth once every 20 years, and each time it occurs in a sign of the zodiac that is always shifted 8 places clockwise from the sign in which it fell the previous time.

With reference to the drawing in Fig.4 (note also the asterisk marked by Kepler for the year 1603), it can be seen that the signs in which every time the conjunction falls are always the same three (in this case are Aries, Leo, Sagittarius), but with the peculiarity that, at every conjunction, there is a movement of each of the three vertices of the triangle in a clockwise direction by 9 .

Since every sign is identified by an arc on the circumference of the Zodiac, to go through the all arc is needed at least an angle of 30: therefore, the conjunction will fall in the same three signs for 10 ten times in a row, which correspond to a 200-year time interval. Starting from the 11 th conjunction, the three signs involved will be the three signs (Taurus, Virgo, Capricorn) immediately following those of before in a clockwise direction, and a new type of Trigon will begin.

After 800 years, the conjunction will again fall in the same three signs from which the counting began, and so the cycle begins again.

Astrologers defined the Fiery Trigon as the 200-year time interval during which Jupiter and Saturn met exclusively in the signs of Fire (Aries, Leo, Sagittarius), attributing to the greater proximity between the two planets a succession of effects on the Sublunar world.

About this, Kepler's thought was that "when planets move the Sublunar nature, they do not do so as forces of nature exerting an effect due to the presence of a receptive thing; rather, they put nature in motion in the same way objects affect the senses, or light affects the eyes, or a sound affects hearing, or heat affects sensation", just as if it were a "natural immaterial effluence" [14].

Despite this, Kepler pointed out an appealing coincidence of events that tended to accompany the beginning of each new cycle of the Fiery Trigon every 800 years:

Main events in the Human History, De Stella Nova, Chapter VII.

\begin{tabular}{c|c|c|l|l} 
Period & Years & $\begin{array}{c}\text { Since the beginning } \\
\text { of the world }\end{array}$ & Key people & $\begin{array}{l}\text { Associated events } \\
\text { (don't attribute them to triangles!) }\end{array}$ \\
\hline 1 & 4000 B.C. & 0 & Adam & Creation of the world. \\
\hline 2 & 3200 B.C. & 800 & Enoch & Robberies, cities, arts, tyranny. \\
\hline 3 & 2400 B.C. & 1600 & Noah & Flood. \\
\hline 4 & 1600 B.C. & 2400 & Moses & Exodus from Egypt. Law. \\
\hline 5 & 800 B.C. & 3200 & Isaiah & Era of the Greeks, Babylonians, Romans. \\
\hline 6 & & 4000 & Christ & Roman dominance, renewal of the world. \\
\hline 8 & 1600 A.D. & 4800 & Charlemagne & Western Empire and Saracen Empire. \\
\hline 9 & 2400 A.D. & 5600 & Rudolf II & Life, lot and desires of us who discuss this. \\
\hline & & 6400 & & $\begin{array}{l}\text { What will become of us, } \\
\text { and of our flourishing Germany? } \\
\text { Who are our successors? } \\
\text { Will they think of us too? } \\
\text { If the world should still stand. }\end{array}$ \\
& & & & \\
\hline
\end{tabular}

The conjunction between Jupiter and Saturn that would initiate the much heralded new Fiery Trigon occurred in December 1603, and after a little less than a year, Mars joined the other two planets on 9 October 1604, placing itself in conjunction with Jupiter.

\subsection{Qualitative observations}

There had been numerous forecastings made by astrologers about the return of the Fiery Trigon, that was supposed to bring great changes, and so everyone was looking at the sky waiting for Mars to join Jupiter and Saturn.

The event was expected to take place in the constellation of Ophiuchus, which had therefore been constantly monitored for months by astronomers and researchers from all over the world. It is due to this close tracking that it was possible to know exactly when the star appeared.

The most authoritative voices were all in agreement in confirming that up to and including 9 October, there were only the three planets, without the presence of anything unexpected.

The observation made on the 10th of October by Brunowsky could not be more detailed since the sky was overcast, and therefore he was not able to investigate further what he thought he had seen. Brunowsky and Schuler continued to monitor the sky, which was unfortunately always covered by clouds. 


\begin{tabular}{cc|l|l}
\hline Date & & Description & Observer \\
\hline 1604 & Sept. 27 & - Distinctly saw Mars, Jupiter and Saturn. & Kepler (Prague) \\
& Oct. 3 & - Mars and Jupiter approaching. & Kepler \\
& Oct. 7 & - Mars and Jupiter approaching. & Johannes Schuler ${ }^{1}$ (Prague) \\
& Oct. 8 & - Mars and Jupiter approaching. & Johannes Brunowsky (Prague) $^{2}$ \\
& Oct. 9 & - Observed Mars, Jupiter ancd Saturn. & Helisus Rslin, Alsazia (France) \\
& & - Observed Mars, Jupiter and Saturn. & David Fabricius (Frisia) \\
& & - Observed Mars, Jupiter and Saturn. & Michael Mstlin, Tübingen (Germany) \\
\hline
\end{tabular}

${ }^{1}$ Kepler's assistant, ${ }^{2}$ Collaborator of the Vice Chancellor of the Emperor.

\begin{tabular}{cc|l|l}
\hline Date & & Description & Observer \\
\hline 1604 & Oct. 9 & $\begin{array}{l}\text { - Mars had finally reached the other two planets. } \\
\text { Oct. 10 Noticed something extremely bright where } \\
\text { the conjunction was taking place }\end{array}$ & $\begin{array}{l}\text { Johannes Brunowsky } \\
\text { (Prague) }\end{array}$ \\
\hline
\end{tabular}

In other parts of Europe, the clearer weather made it possible to see very distinctly what was happening in the sky:

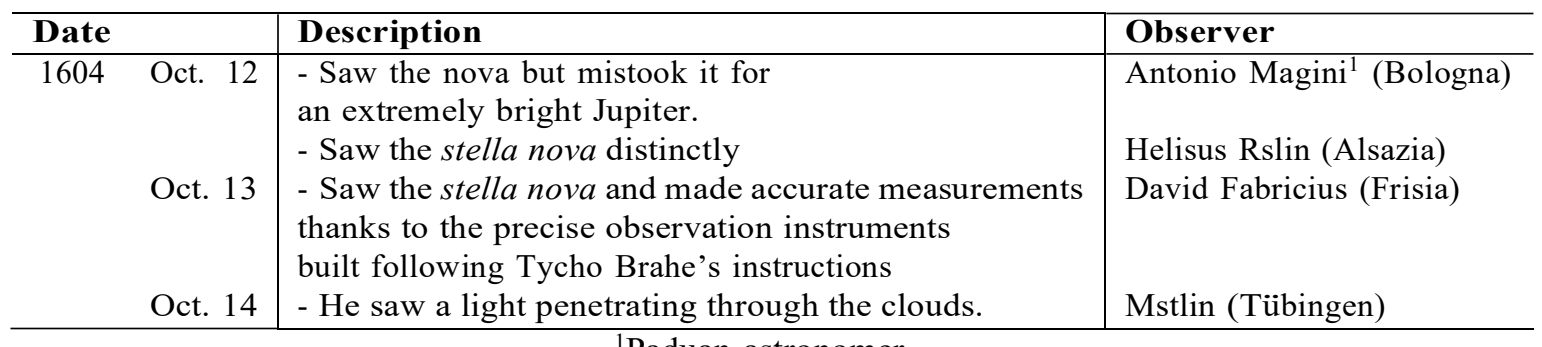

${ }^{1}$ Paduan astronomer.

After a couple of days, the sky above Prague began to clear and Brunowsky went to Kepler to confirm what he had seen on the 10th of October, but when Kepler went to observe for himself, the sky was again covered with clouds, and Kepler was unable to see anything.

Before long, news of this new body appearing in the skies spread everywhere. So, the large number of observers made it possible to accurately describe the following characteristics of shape, colour, size, position and type of light emitted by the star:

- Shape of the star was: it was reported to be perfectly round, with no tail or halos of any kind.

- Light emitted: the nova was described very similar to fixed stars in the way it spread its light, uniform in all directions, and the light was one of the most distinctive features of the star, as it was a pulsating sparkle, so fast that many claimed they had never seen anything like that on any other celestial body.

- Color : it was another astonishing aspect about the star, whose colour Kepler defined "variable as the colours of the rainbow". Its colour constantly shifted from a yellow-red to an intense yellow and then to a purple, that turned red a moment later, while when the star rose in altitude, the predominant colour became white.

- Size of the star: observers reported that the comparison between the star and the three planets showed that the star far exceeded them in size, but was still smaller than Venus.

- Position: Kepler reported that due to its size, light intensity and colours, the star could only be located among fixed stars.

From October 1605 to March 1606, the nova gradually became smaller and smaller and more difficult to detect. As the human eye was the only observational instrument available, it was not possible to give a precise date for its extinction. 


\begin{tabular}{cc|l|l}
\hline Date & & Description & Observer \\
\hline 1604 & Oct. 16 & - He was finally able to see nova. & Mstlin (Tübingen) \\
& Oct. 17 & - For the first time, he saw the nova. & Kepler (Prague) \\
\hline
\end{tabular}

\subsubsection{Venus mistaken for the new star}

In the early days of the second decade of October, a confusing phenomenon occurred: Venus was very low on the horizon, so low that it was much larger and brighter than usual, to the point that it was visible even in broad daylight.

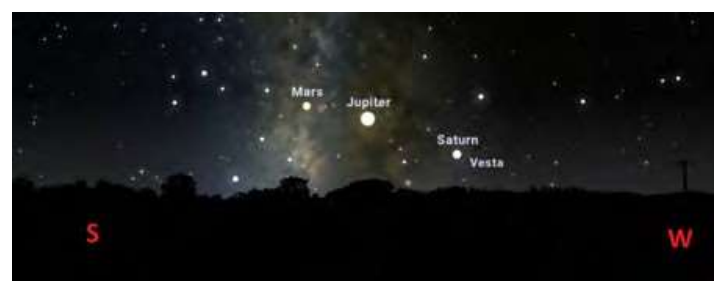

(a) 19.10.1604, SW, 06:50 p.m.

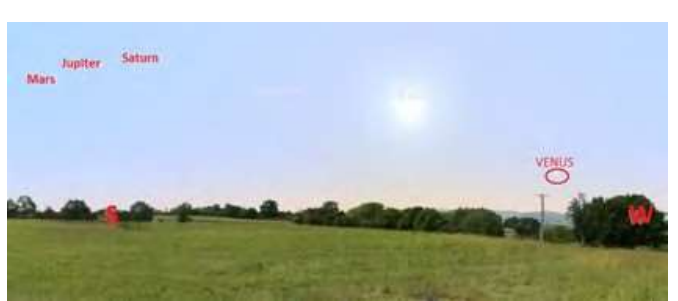

(b) 19.10.1604, SW, 03:00 p.m.

So while astronomers and experts were looking westwards at night towards the new star (a), ordinary people were looking at Venus during the day (b) mistaking it for the nova. Once it was realised that it was not the star but Venus, the event was nonetheless included in the list of miraculous signs that were keeping everyone's eyes glued to the sky, contributing to increase the feeling of disbelief surrounding such events, because the nova was happening just a few months after the return of the Fiery Trigon, which was expected to bring something wonderful, and in fact, at least for the moment, was not disappointing the expectations.

\subsection{Kepler's conjectures}

\subsubsection{Nova's sparkle and composition}

The star had an extremely particular type of luminosity: sparkling.

The cause of that particular type of light was considered to be the size, the brightness, the movement of the body, the matter of the star and the movement of the light itself inside the body. The movement of the body and the movement of the light within it were identified as the main causes of the sparkling: Kepler believed that the cause of the twinkling was contained in the stellar bodies themselves, for he stated that in every celestial body there was a kind of "natural light power, which does not spread without motion" [14].

When it comes to the material composition of the star, due to what has been said about the need for some kind of internal movement that was essential because of the pulsating nature of the nova, Kepler had no doubt that the star was either a flame or a body that contained that pulsating movement, be it contraction or very fast rotation.

Underlying this was the idea of "some kind of life or the activity of a forming, moving or animating faculty" [14].

Kepler was more oriented towards believing that the star was a flame, because at some point it went out just like a flame that has run out of fuel.

But it could only be a flame with a well-confined body and matter of its own, for does not exist flame capable of burning without matter. So, the hypothesis that Kepler considered most likely were that "the new star received either a fatty substance that was ignited by the cold like shooting stars, or a watery substance in which the sun or its inner fire was reflected" [14].

On one hand, Kepler supported the idea that the matter of the nova had something in common with the matter of shooting stars, because they shine very brightly and clearly, just like the nova. But due to its shimmering and rainbow colours, Kepler associated it with the characteristics of a water-rich substance.

\subsubsection{Kepler's Universe is finite}

Kepler suggested that the way stars appeared in relation to their relative positions depended only on the point of observation, i.e. the Earth, and that any observers placed on any of the other stars, especially 
distant stars, would have seen a completely different sky. Hence the statement that "the place where we live always has something special about it, something incommunicable to all in all that infinity” [14].

Kepler asserted that for the observer on Earth any measurement of the diameter of a fixed star would have given almost the same value, estimated at two minutes of arc. Once the diameter, measured by sextant, was known, an estimate of the distance was immediately given as about a thousand or two thousand times the value of the diameter. Extending this consideration to all possible fixed stars implied asserting that they had all to be confined within a finite distance.

In fact, Kepler argued that, however large the universe could be, the observer on Earth would have seen the fixed stars arranged non-uniformly: if the universe was infinite, it could only be uniform, and therefore both the Earth and any other observer on any of the fixed stars would have seen all the other celestial bodies arranged around him in a uniformly spherical manner.

In the light of this consideration, Kepler was certain that the universe was bounded inwards, i.e. hollowed out towards the sun and planets, and that the Milky Way ran between them in an unbroken circle passing through the centre of the circle of fixed stars, thus enclosing the Earth in its midst.

Thus, both the Milky Way and the fixed stars necessarily had the function of an ultimate boundary.

Kepler also claimed that if what is contained within this boundary on the inside is finite, the same must be true on the outside, because if it was possible to see an infinitely distant star, it would have meant that it necessarily had to be infinite in size and mass on the basis of the relation

$$
\text { diameter }=\frac{\text { distance }}{1000(\text { or } 2000)}
$$

This, however, could not be compatible with the fact that all stars had a well-defined and limited form, for if the star that has an infinite distance is actually seen, the very fact that it is seen implies that the eye detects it as having a finite size. Yet, from the hypothesis of infinite distance it follows that the diameter must necessarily also be infinite, whereas the eye sees it as being of finite size.

Hence the absurdity, for Kepler, of the initial hypothesis. So the Universe can only be finite.

\subsubsection{The stella nova is a brand new body}

What was evident was that the mass of the star had to be composed of an enormous amount of matter, and it became immediate to wonder where that matter had come from.

Kepler, which estimated the size of the nova to be similar to that of any comet, rejected the hypothesis that such matter could have come from the Earth, as the Earth was too small to have provided it.

The two opposing hypotheses most in evidence at the time on this subject were the following:

I. Everything that had to be created was created at the instant of Creation, so the nova had always existed, but for some reason it was not visible, and it became visible when God wanted to use it to convey some kind of message.

II. Others claimed that both new light and new bodies could appear in the sky.

Tackling the subject of how it was possible for new bodies to be created, and thus an addition of matter in a place where there was none before, opened up extremely delicate questions, and Kepler was very cautious about pursuing such avenues.

In fact, he often used the word "perhaps", and in this case he asserted that if a new body had appeared where there was none before, the reason could 'perhaps' be that it had arisen from that "perfect power of divine majesty with which God in the beginning created the whole Universe" [14].

Actually, for Kepler there was no reason to believe that a new body was already existing before it became visible, nor that, once consumed, it could continue to exist indefinitely. He also rejected the possibility that a body could momentarily switch off and then switch on again at a later time.

\subsubsection{Universe as a store of matter for new stars}

Having rejected the idea that the matter of which the stars are composed was eternal, Kepler analysed all the other possibilities.

Kepler asserted that the matter of which stars were composed did not come from the Earth, so it could only be matter originating in the Heavens.

"Without matter there is no creation", therefore a storehouse of such matter had necessarily to exist, and one possibility was that it could be identified in the very dense ether of which the Milky Way was composed, therefore considered perfectly suitable to create new formations.

There were two objections to this view: the first, posed by Fabricius, brought the example of a thirdmagnitude star observed on the morning of 13 August 1596 and disappeared in October of the same year, located in a zone of the sky very far from the Milky Way. So, asked Fabricius, how was possible for this star being so distant from the store of matter from which it had originated? 
The second objection was that if it was assumed that the matter of the new stars was indeed matter that previously had belonged to the Milky Way, then considering the very large number of stars that in the course of the previous 1400 years had been ignited and formed from it, the Milky Way should have had a diminution of its own matter of such considerable quantities as to be noticeable to the naked eye.

And if the number of new bodies appearing was not yet so great as to make the diminution of matter in the Milky Way detectable, then surely in the distant future it would have been, until at some point the Milky Way would have lost all its matter bit by bit.

It was from these two objections that Kepler was persuaded that the ability to provide matter for new stars was not just the prerogative of the Milky Way, but of all the Universe.

\subsection{Conflict with Aristotelians, Astrologers and Epicureans}

One of the aspects on which astronomers such as Galilei and Kepler found themselves in strong opposition to the Aristotelians of the time, was the distance of this New Star from the Earth. It was still a widespread belief that everything in the high celestial spheres was immutable.

Following the immutability hypothesis, the sudden appearance of a new celestial body could only concern the sublunar spheres. To show the serious unreliability of this belief, the most immediate counterevidence was the method of parallax.

The extremely simple way in which Kepler explained how this method worked in practice is as follows:

Hold your head still, close your eyes alternately and look with the open eye at the tip of your nose. If one looks with the right eye, the nose will be seen on the left part of a book or the floor; but if one looks with the left eye, the nose will cover the right part of the book. As often as you change your eyes, it looks as if the nose is jumping, even if it remains motionless.

After that, you don't look at your nose, but at your unmoving thumb, which has to stick out a little further from your face. If you change eyes, the thumb will do the same as the nose before, but its jumps will not be quite as big. Common sense concludes from this that the thumb is further away than the nose because it makes a smaller change of jump [parallax] or a change of the place seen.

What for us are the two eyes, for astronomers are two places in space, and what in our example are the nose and the thumb, for astronomers are the moon and another, more distant star. What here is book or ground, is the fixed star sphere for astronomers. The thumb and the nose are still far from the ground or the book, even if, seen with one eye each, they seem to touch and cover them; in the same way the planets do not stand up in the ether between the fixed stars themselves, but far below them, yet seem to float high up in the ether" [14].

The immutability of the heavens was one of the pillars of the Aristotelian creed, but Kepler argued that what was currently referred to as 'Aristotelian' doctrine and its followers were actually much more unshakable than Aristotle himself could have been if there had been the chance to have a confrontation with him.

Using a metaphor, Kepler wrote: "It is the case with plaster that when it is newly poured out, any form can be imprinted on it, but when it becomes hard, it resists all imprinting. Thus, as long as views come out of the mouths of philosophers, they can still be easily improved; but once they have been taken up by the disciples, they become as hard as stone and cannot be so easily broken up by any reasons" [14].

The reason why, said Kepler, Aristotle was so convinced that the heavens were immutable, where nothing disappeared and nothing new appeared, was on the basis of what had been reported in the previous centuries, where indeed nothing new had appeared.

But, said Kepler, if Aristotle had been present to observe, for example, the nova appearing in Ophiuchus, he would not have insisted on his old convictions and would have changed his mind instantly.

Thus, what Kepler accused Aristotle's followers of was seeking tortuous explanations to justify a belief that denied the evidence of the facts.

The nova appeared at a time when all mankind was waiting for all those wonderful, mysterious new events that astrologers predicted would have come as a result of the Great Conjunction. And in this regard, the nova was lit on the very day when Mars was expected to pass Saturn and then reach Jupiter. There were, in short, many reasons to look upon that Star as a truly powerful and significant event.

Kepler, in the last chapters of the De Stella Nova, went on to address in a lucid and analytical way the various voices that were then speaking out about what the reasons for Nova's appearance might be and, above all, what the consequences of its presence would be, especially for the sublunar world.

To the question "Why did the nova appeared at the very moment of the Great Conjunction?", astrologers answered by asserting that the cause of the creation of the nova was to be traced back to the 
conjunction of the three planets, but they did not give explanation to how such a formation actually occurred.

Even assuming that the nova was a consequence of the conjunction, the question became "who or what decided that the nova should appear at a visible point in the conjunction?". The first answer was to assert that some creative reason had taken the trouble to observe how the conjunction looked from Earth and decided to create the star there.

Kepler excludes completely what were the beliefs of astrologers: both that the nova was generated by the conjunction of the three planets in the manner of two parents conceiving a child, as well as the possibility that there could have been a creation by a particular combination of light rays.

For, if creation was linked to the encounter of light rays, this was a phenomenon that occured continuously in the heavens. So, asked Kepler, why don't we see new stars appearing all the time?

Again, the theory proposed by astrologers couldn't be explained in any way and had to necessarily resort to the idea of a divine reason that was responsible for the three planets creating the star.

For Kepler, the Earth was a privileged vantage point for observing the Conjunction, which appeared in that exact configuration only to those observing it from Earth. The relative positions of the three planets only appeared that way when viewed from Earth. Therefore, the conjunction, as a geometric design in the sky, was exclusively a matter of observation point.

Looking at it from another planet, there would be no conjunction. So, once it was established that conjunction was a purely relative subject, did it still make sense to attribute any kind of meaning to it? And, more importantly, how could an event that only makes sense when viewed from Earth be linked to the appearance of the new star in the sphere of fixed stars?

For Kepler, the answer is that it could not, and that the conjunction alone can in no way have given rise to the nova.

This hypothesis is countered by the School of Epicurus, which attributed the presence of the nova exclusively to chance.

The way Kepler wrote about this beliefs was a clear indictment of the Epicureans, which Kepler considered to be guilty of a lack of wonder, but above all of considering space and time infinite, so that "if one presupposes eternity, than everything that is possible must occur, for example alla forms of planetary conjunctions" [14]. Such an idea, that every event had the same value as every other, because sooner or later, by waiting an infinite amount of time, any event would take place, was unacceptable to Kepler.

Kepler recognised that order could have born out of chaos, but it will never be as elegant and beautiful as something that was created and built to be so. That the star joined the three planets could have been an event born of chance, but for Kepler such a perfect and magnificent coincidence in both place and time could not be a random event.

Combining all the coincidences with the fact that the exact positional relationship between the planets and the star was visible in that exact way only and exclusively from Earth, led Kepler to conclude that such a spectacle was created for the exclusive benefit of mankind.

\subsection{Position of the new star}

The star appeared in S-W direction, in the constellation of Ophiuchus.

The data available in De Stella Nova are found in Chapters XI, XII and XIII, and include both those recorded in Prague by Kepler and his collaborators (including both measurements of the stella nova's distance to other fixed stars and the distance to the three neighbouring planets Mars, Jupiter and Saturn), and the data collected by Fabricius ${ }^{3}$ who measured the distance between the nova and the stars that appeared brighter.

From the collected data of relative positions between the nova and fixed stars and between the new star and the three planets, Kepler obtained several estimates of the position of the star which are shown in the following table, where have also been included, for practical reasons, the average values of the data he provided:

${ }^{3}$ David Fabricius (1564-1617), Dutch astronomer and pupil of Tycho Brahe 


\begin{tabular}{|c|c|c|c|}
\hline Date & Planet or stars used as reference & Longitude of the nova & Average value \\
\hline 1604 Oct. 17 & $\begin{array}{l}\text { Jupiter } \\
\text { Mars } \\
\text { Saturn } \\
\text { Sagittarius's shoulder } \\
\text { Ophiucus' right knee }\end{array}$ & $\begin{array}{l}1738_{3}^{13} \\
1736_{4}^{1} \\
1746^{\prime} \\
1741^{\prime} \\
1742^{\prime}\end{array}$ & $1740^{\prime} 48^{\prime \prime}$ \\
\hline 1604 Oct. 18 & $\begin{array}{l}\text { Jupiter } \\
\text { Sagittarius's shoulder } \\
\text { Ophiucus' right knee }\end{array}$ & $\begin{array}{l}1739^{1}{ }^{\prime} \\
1739^{\frac{1}{2}} \\
1738^{\prime} \text { or } 1739^{\prime}\end{array}$ & $1738^{\prime} 57^{\prime \prime}$ \\
\hline 1604 Oct. 21 & $\begin{array}{l}\text { Jupiter } \\
\text { Sagittarius's shoulder } \\
\text { Ophiucus' left knee }\end{array}$ & $\begin{array}{l}1740^{1}{ }^{\prime} \\
1739^{\prime} \\
1742^{\prime}\end{array}$ & $1740 ’ 26 ”$ \\
\hline 1604 Oct. 27 & Jupiter & $1743_{3}^{29}$ & 1743 '40” \\
\hline $1605 \quad$ Feb. 12 & $\begin{array}{l}\text { Eagle } \\
\text { Scorpio's heart }\end{array}$ & $\begin{array}{l}1740_{\overline{3}}^{13} \\
1745^{\prime}\end{array}$ & $1742^{\prime} 40^{\prime \prime}$ \\
\hline
\end{tabular}

A further average of the average latitudes gives a value of 1740'1", which fits well with the final risult reported by Kepler, who estimated the star's latitude at 1740 '.

In the following table are collected the measurements recorded by Fabricius, which used exclusively the position of the star with respect to the fixed stars without considering, unlike Kepler, the planets:

\begin{tabular}{lc}
\hline Celestial bodies & Distance \\
\hline Nova and Ophiucus' head & $340^{\prime}$ \\
Nova and Ophiucus' left knee & $1646^{\prime}$ \\
Nova and Eagle & $4545^{\prime}$ \\
Nova and Scorpio's heart & $1450 \frac{1}{2}$, \\
Nova and Libra's north & $3414^{\prime}$ \\
Nova and Libra's south & $384^{\prime}$ \\
Nova and the northermost Scorpio's forehead & $1959^{\prime}$ \\
Nova and Ophiucus' right knee & 732 ' \\
\hline
\end{tabular}

Kepler used the data reported by Fabricius to extrapolate further estimates of stella nova's position:

\begin{tabular}{ll}
\hline Stars used as reference & Longitude of the nova \\
\hline Ophiucus' knee & $1741^{\prime}, 17366^{\prime}$ \\
Scorpio's heart & $1741^{\prime}$ \\
Libra's north & $1736 \frac{1}{2}$ \\
Libra's south & $1737^{\prime}$ \\
Nothermost Scorpio's forehead & $1737 \frac{1}{3}$, \\
Ophiucus' right knee & $1746 \frac{2}{3}$, \\
\hline
\end{tabular}

The average of the measurements reported leads to a value of 1739'20".

The value obtained by Kepler (1740') and that obtained with Fabricius' data (1739'20') were extremely compatible. Kepler, in conclusion, identified the position of the nova in the following values of right $\operatorname{ascension}(\alpha)$ and $\operatorname{declination}(\delta)$ :

$$
\alpha=25647^{\prime}(=17 \mathrm{~h} 7 \mathrm{~m} 8 \mathrm{~s}) \quad \delta=211 \frac{1}{2} \text { 'south (= }-211^{\prime} 30 \text { ') } .
$$

\section{The data on SN1604: a comprehensive analysis}

In this chapter we put together, with a modern interpretation, the early data on SN1604. We shall include also the Chinese and Korean data.

\subsection{Position}

As reported in Chapter 2, Kepler derived from his observational data the position of the nova, assigning it the following values of right $\operatorname{ascension}(\alpha)$ and declination $(\delta)$ :

$$
\alpha=17 \mathrm{~h} 7 \mathrm{~m} 8 \mathrm{~s} \quad \delta=-211 \frac{1}{2}{ }^{\prime}\left(=-211{ }^{\prime} 30^{\prime \prime}\right)
$$


This value is recognized as being of great historical importance, but subsequent reanalysis of the data [2] had shown their lack of precision also because of the numerous measurement errors. In addition, Kepler, when assessing the position of the nova relative to other celestial bodies, included the three planets Mars, Jupiter and Saturn, thus increasing the chances of error.

The position of the nova was recalculated in 1865 by E. Schoenfeld, then in 1934 by O. Schlier, and finally in 1937 by S. Boehme. All of them have decided not to take into account, for the purposes of the calculation, the position measurements of the nova with respect to the planets, but only those with respect to the stars. Schoenfeld and Schlier used only the measures provided by Fabricius, while Boehme made corrections to Kepler's data. The position of the nova is therefore historically identified with the following values in equatorial coordinates:

$$
\alpha=17 \mathrm{~h} 26 \mathrm{~m} 44.9 \mathrm{~s} \quad \delta=-2125^{\prime} 55^{\prime \prime} \pm 1 ' .
$$

Later Blair [3] expressed the position of the Star in terms of the Galactic longitude $(l)$ and latitude (b): $l=+4.5, b=+6.8$. In order to compare with the values of right ascension and declination reported so far, the values quoted by Blair have been inputed in the LAMBDA-Tool Conversion Utilities provided by NASA, which returned the following values:

$$
\alpha=262.99293=17 \mathrm{~h} 31 \mathrm{~m} 58 \mathrm{~s} \quad, \quad \delta=-21.53082=-2131^{\prime} 50 ’ .
$$

\subsection{Light curve}

Briefly summarizing the highlights in the evolution of the nova's luminosity:

- it appeared in SW direction on 9/10 October, with brightness increasing to a peak around the second half of October, when it was reported to be even a little brighter than Jupiter;

- from November 1604 to January 1605, it was no longer visible in Europe, and shortly before disappearing from the view, the Star had been defined as equal to Jupiter in size and brightness;

- when it reappeared in January, it was located eastwards, and had become much more dim;

- over the months, its brightness continues to decrease, and reaches mag 5 around October 1605;

- In February 1606 it becomes definitely no longer visible to the naked eye.

The following two images, obtained by means of the Stellarium simulation, offer a visual comparison of the new star's position on 9 October 1604, the day of its first detection, and on 4 February 1605, when it had become extremely dim. The reconstruction is based, respectively, on what is described by Altobelli ${ }^{4}$ (a) and Galilei ${ }^{5}$ (b):

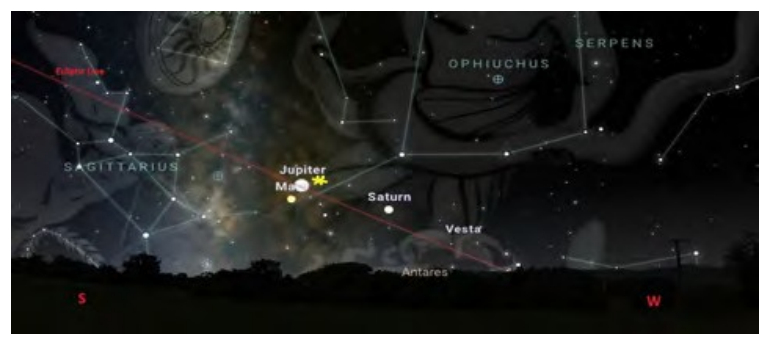

(a) 9.10.1604, SW, 07:00 p.m.

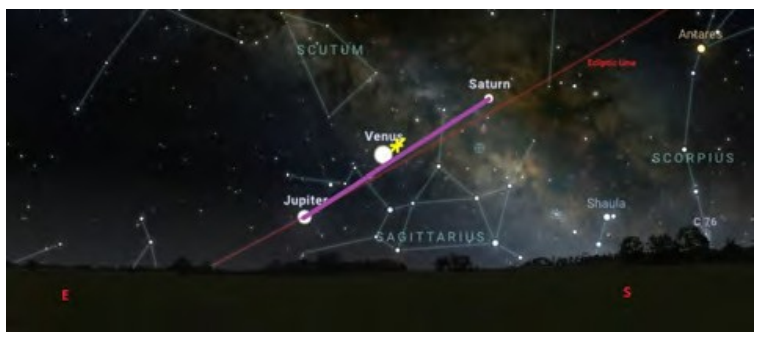

(b) 4.02.1605, ES, 06:30 a.m.

Baade [2] made a collection of descriptive observations of the new star's brightness from the time of its appearance to about a year later.

The aim was to reconstruct the temporal evolution of the course of the luminosity of the nova during the observation period what astronomers call "light curve". A first attempt of a conversion that allows to pass from the purely descriptive terms used by astronomers of the 1600 to their quantification, is provided by Baade, which adopted the following convention:
Much brighter
Brighter
$-0.75 \mathrm{mag}$.
Not much brighter
$-0.50 \mathrm{mag}$.
$-0.25 \mathrm{mag}$.

\footnotetext{
${ }^{4}$ Letter n. 107, see the Appendix.

${ }^{5}$ See Appendix: On 4 Feb. 1605, Galilei reported that 'in the morning, one hour before sunrise, the new star was halfway along the line joining Saturn and Jupiter and extending northwards to Venus'.
} 
Next, the magnitudes of Mars, Jupiter, Saturn, $\alpha$ Sco, $\alpha$ Boo, $\alpha$ Vir, $\zeta$ Oph, $\eta$ Oph, $\xi$ Oph and Venus used as a reference by Baade and, for the sake of completeness, the values provided by Stellarium:

\begin{tabular}{|c|c|c|c|c|}
\hline \multirow[t]{7}{*}{ Date } & & Planet/Star & Baade(mag.) & Stellarium(mag.) \\
\hline & & $\alpha \mathrm{Sco}$ & +1.22 & +0.97 \\
\hline & & $\alpha$ Boo & +0.24 & +0.11 \\
\hline & & $\alpha \mathrm{Vir}$ & +1.21 & +0.89 \\
\hline & & $\zeta \mathrm{Oph}$ & +2.70 & +2.56 \\
\hline & & $\eta \mathrm{Oph}$ & +2.63 & +2.44 \\
\hline & & $\xi \mathrm{Oph}$ & +4.46 & +3.38 \\
\hline \multirow[t]{19}{*}{1604} & Oct. 8 & Mars & ב... & +0.77 \\
\hline & & Jupiter & -1.87 & -1.87 \\
\hline & Oct. 9 & Mars & +0.90 & +0.77 \\
\hline & & Jupiter & $\ldots$ & -1.87 \\
\hline & Oct. 10 & Mars & $\ldots$ & +0.77 \\
\hline & & Jupiter & $\ldots$ & -1.86 \\
\hline & Oct. 11 & Mars & $\ldots$ & +0.78 \\
\hline & & Jupiter & $\ldots$ & -1.86 \\
\hline & Oct. 12 & Mars & $\ldots$ & +0.78 \\
\hline & & Jupiter & $\ldots$ & -1.85 \\
\hline & Oct. 15 & Mars & $\ldots$ & +0.80 \\
\hline & & Jupiter & -1.84 & -1.84 \\
\hline & & Venus & $\ldots$ & -4.31 \\
\hline & Oct. 17 & Mars & $\ldots$ & +0.81 \\
\hline & & Jupiter & $\ldots$ & -1.83 \\
\hline & Nov. 9 & Mars & $\ldots$ & +0.90 \\
\hline & & Jupiter & $\ldots$ & -1.75 \\
\hline & Nov. 12 & Mars & $\ldots$ & +0.91 \\
\hline & & Jupiter & -1.73 & -1.74 \\
\hline \multirow[t]{2}{*}{1605} & Jan. 13 & Saturn & +0.78 & +0.55 \\
\hline & Jan. 21 & Saturn & $\ldots$ & +0.56 \\
\hline
\end{tabular}

The conversion devised by Baade therefore consisted in adding the value indicated in the legend to the apparent magnitude of the planet/star that is mentioned in the description. For example, on 28 March 1605 is reported "Not much brighter than $\eta$ Oph", so to the mag of $\eta$ Oph $(+2.63)$ must be added the conversion associated with the phrase "Not much brighter" $(-0.25)$, so as to obtain the value of the magnitude of the nova on the selected date:

$$
2.63-0.25=2.38 \sim 2.4 \text {. }
$$

The values that Baade derived from its own conversion are listed in the following table. In the second column there are also some values in brackets, which are those that Baade has decided not to consider for the calculation as being too oversized or considered unreliable.

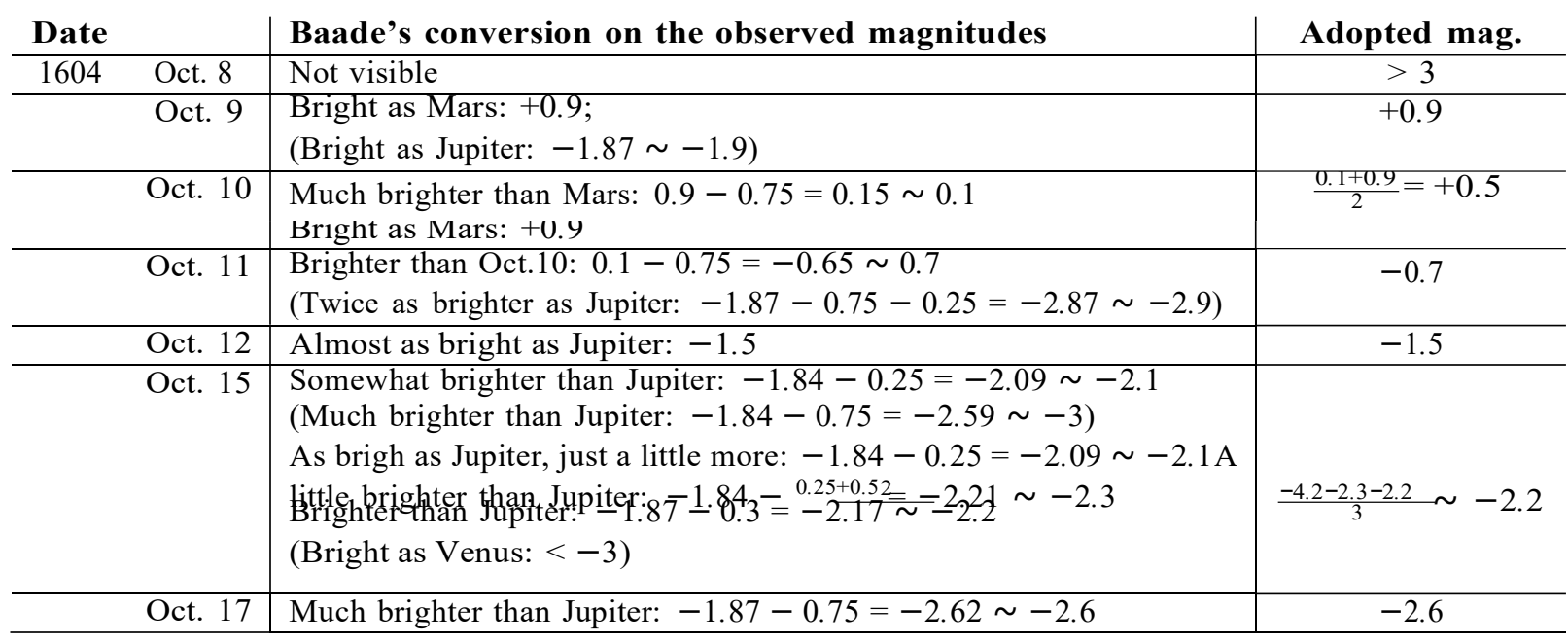




\begin{tabular}{|c|c|c|}
\hline Date & Baade's conversion on the observed magnitudes & Adopted mag. \\
\hline Jan. 3 & $\begin{array}{l}\text { Brighter than } \alpha \text { Sco: }+1.22-0.5=0.72 \sim 0.7 \\
\text { Much fainter than } \alpha \text { Boo: }+0.24+0.75=0.99 \sim 1.0\end{array}$ & $\frac{\mathrm{v} .1+1}{2}=0.85 \sim+0.9$ \\
\hline Jan. 13 & $\begin{array}{l}\text { Brighter than } \alpha \text { Boo: }+0.24-0.5=-0.26 \sim-0.3 \\
\text { Brighter than Saturn: }+0.78-0.5=0.28 \sim+0.3\end{array}$ & $\frac{-0.3+0.3}{2}=0$ \\
\hline Jan. 14 & Bright as Mars in Oct. 1604: +0.9 & +0.9 \\
\hline Jan. 21 & $\begin{array}{l}\text { About bright as } \alpha \text { Sco: }+1.2 \\
\text { (A little brighter than Saturn: }+0.78-0.25=0.53 \sim+0.5 \text { ) }\end{array}$ & +1.2 \\
\hline End of Jan. & As bright as $\alpha$ Vir: +1.2 & +1.2 \\
\hline March 20 & $\begin{array}{l}\text { Not much brighter than } \zeta \text { Oph: }+2.7-0.25=2.45 \sim+2.4 \\
\text { Not much brighter than } \eta \text { Oph: }+2.63-0.25=2.38 \sim+2.4\end{array}$ & +2.4 \\
\hline March 27 & $\begin{array}{l}\text { Not much brighter than } \zeta \text { Oph: }+2.7-0.25=2.45 \sim+2.4 \\
\text { Not much brighter than } \eta \text { Oph: }+2.63-0.25=2.38 \sim+2.4\end{array}$ & +2.4 \\
\hline$\sim$ March 28 & Not much brighter than $\eta$ Oph: $+2.63-0.25=2.38 \sim+2.4$ & +2.4 \\
\hline April 12 & As bright as $\eta$ Oph: $+2.63 \sim+2.6$ & +2.6 \\
\hline April 21 & As bright as $\eta$ Oph: $+2.63 \sim+2.6$ & +2.6 \\
\hline Aug. 12-14 & As bright as $\xi$ Oph: $+4.46 \sim+4.5$ & +4.5 \\
\hline Aug. 29 & About as bright as $\xi$ Oph: $+4.46 \sim+4.5$ & +4.5 \\
\hline Sept. 13 & Fainter than $\xi$ Oph: $+4.46+0.5=4.96 \sim+5$ & +5 \\
\hline Oct. 8 & $\begin{array}{l}\text { Fainter than } \xi \text { Oph: }+4.46+0.5=4.96 \sim+5 \\
\text { As bright as } \xi \text { Oph: }+4.46 \sim+4.5\end{array}$ & $\frac{\partial+4.5}{2}=4.75 \sim+4.8$ \\
\hline
\end{tabular}

With these data, Baade was able to reconstruct the corresponding light curve, using an already known light curve as a support: the curve in the following figure is the light curve, appropriately fitted to Baade's data, of the type Ia supernova detected a few years earlier (1937) in the galaxy IC 4182.

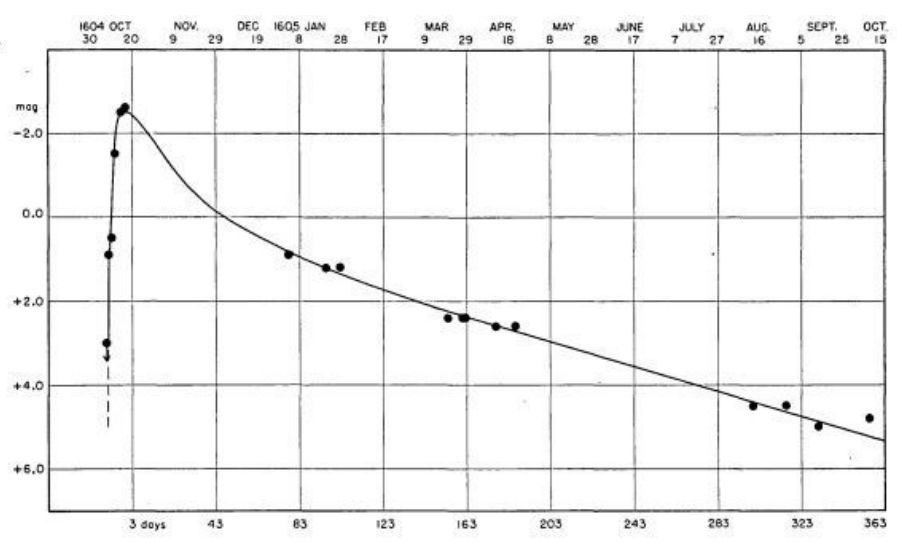

Figure 6: Light curve of Supernova Ophiuchi of 1604, Baade (1943)

The result was that the degree of agreement between the data Baade had obtained and the Type Ia supernova light curve used as a guide was extremely high.

In concluision, according to Baade's data the supernova was discovered about a week before it reached its maximum luminous intensity, which from the table appears to have been October 17, 1604. All who observed the nova agreed that after October 15 there were no significant increases in brightness. Thus, the magnitude peak had to be just a little more than the $2.2 \mathrm{mag}$. value for October 15 th: averaging all the magnitude values reported for 15 and 17 October, the result for the maximum brightness of the star is $-2.25 \mathrm{mag}$, with an error, assigned by Baade, of about $0.25 \mathrm{mag}$.

The lack of data in the period late October 1604 - early January 1605 is due to the fact that the new star was hidden by the Sun, and by the time it reappeared it was extremely dim.

An important conclusion from observing the previous light curve is that the nova of 1604 follows the typical pattern of Type I supernovae, summarized in the following trends (Baade 1943):

- the time duration of the maximum values is extremely short;

- the maximum values differ little from each other; 
- after about 80-100 days after the maximum value, the difference in mag between one day and the next has an almost constant linear trend: $(+0.0137 \pm 0.0012) \mathrm{mag}$.

\subsection{Including the data from Chinese and Korean astronomers}

Compared to its first sighting in Europe, the nova was detected in China the next day and 3-4 days later in Korea.

SN1604 was recorded by Chinese astronomers in Ming Shenzong Shilu vol. 400, 404 and 412, and in Ming Shi vol. 27 [20].

Korean records of SN1604 were sistematically taken almost daily in the first half year. There are more than 130 records. The main records are in Sonjo Shilu vol. 178-185.

The Chinese and Korean data were extremely accurate, rich in descriptive details, and lasted systematically for about a year.

Date

Chinese Description[20][2]

1604 Oct. 10 "At night, a strange star appeared

in the SW direction, as large as a pellet bomb,

with orange color and was called "Guest star".

"A star was seen in the degrees of the stellar

division Wei. It resembled a round ball. Its colour

was reddish yellow".

"It was seen in the southwest until the 10th moon [October 27 - November 26, 1604] when it was no longer visible. In the 12th moon, day Sin Yew [February 3, 1605] it again appeared in the southeast, in the stellar division $\mathrm{Wei}^{6}$.

\begin{tabular}{|c|c|c|}
\hline Date & & Chinese Description[20][2] \\
\hline 1605 & $\begin{array}{l}\text { from March } 24 \\
\text { Oct. } 7\end{array}$ & $\begin{array}{l}\text { "Tonight it was seen in SE direction, rotated } \\
\text { with the sky, as large as a pellet bomb with } \\
\text { yellow color and less brightness in the Lunar } \\
\text { Mansion of Wei." } \\
\text { "It gradually faded away. " } \\
\text { "Tonight it was out of sight. It was seen in the Lunar } \\
\text { Mansion of Wei since Oct. 10, 1604: it appeared in the } \\
\text { SW direction ar } 7-9 \text { pm rotated westward with the sky, } \\
\text { until on the } 10^{\text {th }} \text { lunar month it sank and was not } \\
\text { seen in the evening. In the } 11^{\text {th }} \text { lunar month, it } \\
\text { appeared at } 3-5 \text { am in the SE direction. During the } \\
2^{\text {nd }} \text { lunar month of the current year it became faint } \\
\text { and now is fully extinguished." }\end{array}$ \\
\hline
\end{tabular}

Korean data show comparisons of brightness with different planets, precise information on the position and sometimes even the condition of advantage/ disadvantage in observation due to the weather situation of the moment.

\footnotetext{
${ }^{6}$ The stellar division Wei extends from about $\alpha=16 h 40 m$ to $\alpha=18 h$, and from $\delta=-20$ south into the constellation Ara, that is about $\delta=-53.58$
} 
Date $\quad$ Korean Description[20]

1604 Oct. 13 "At night, at 7-9 pm a guest star appeared at 10 degrees in Lunar Mansion Wei, 110 degree polar distance, smaller than Jupiter, orange color, scintillating".

Oct. 14 "At 7-9 pm, it was seen above the Tianjiang stars, at 11 degrees in LMW, 109 degrees polar distance, smaller than Jupiter, yellow color, scintillating”.

Oct. 16 "From the beginning of evening until 7-9 pm, it was thundering and lighting. After, the guest star was outcropped in a rift of clouds, smaller than Jupiter. Its position could not be measured because of the clouds opening and closing".

Oct. 17-18 "It was as large as Jupiter".

Oct. 19 "It was larger than Jupiter".

Oct. 28-31 "It was as large as Venus and gloriously radiant".

Dec. 4 "It was nearby the sun. It sank in the west before evening".

Dec. 26 "Before dawn, it reappeared in the eastern. Was larger than Antares ( $\alpha$ Sco)". seen in the evening. In the $11^{\text {th }}$ lunar month, it appeared at 3-5 am in the SE direction. During the $2^{\text {nd }}$ lunar month of the current year it became faint and now is fully extinguished."

1605 Apr. 22-23 "At 9-11 pm it looked like $\tau$ Sco and yellow color".

May 2 "It was faintly seen through the rift of clouds at 3-5 pm".

\subsection{A modern interpretation}

Ruiz-Lapuente [17] compared the historical records gathered by European, Chinese and Korean astronomers at the time of the explosion in 1604 with the family of SNe Ia as known today.

The light curve of SN 1604 has been reconstructed in a comprehensive analysis using the historical data collected at the time of observation of the outburst. By comparing with templates coing from other supernovae (Fig. 7), Ruiz-Lapuente concluded that that this event looks like a normal supernova Ia (a Type Ia supernova originating from the fusion of two stellar objects one of which is a white dwarf), and obtained an estimate $d=(5.0 \pm 0.7) \mathrm{kpc}$ for the distance to the explosion.
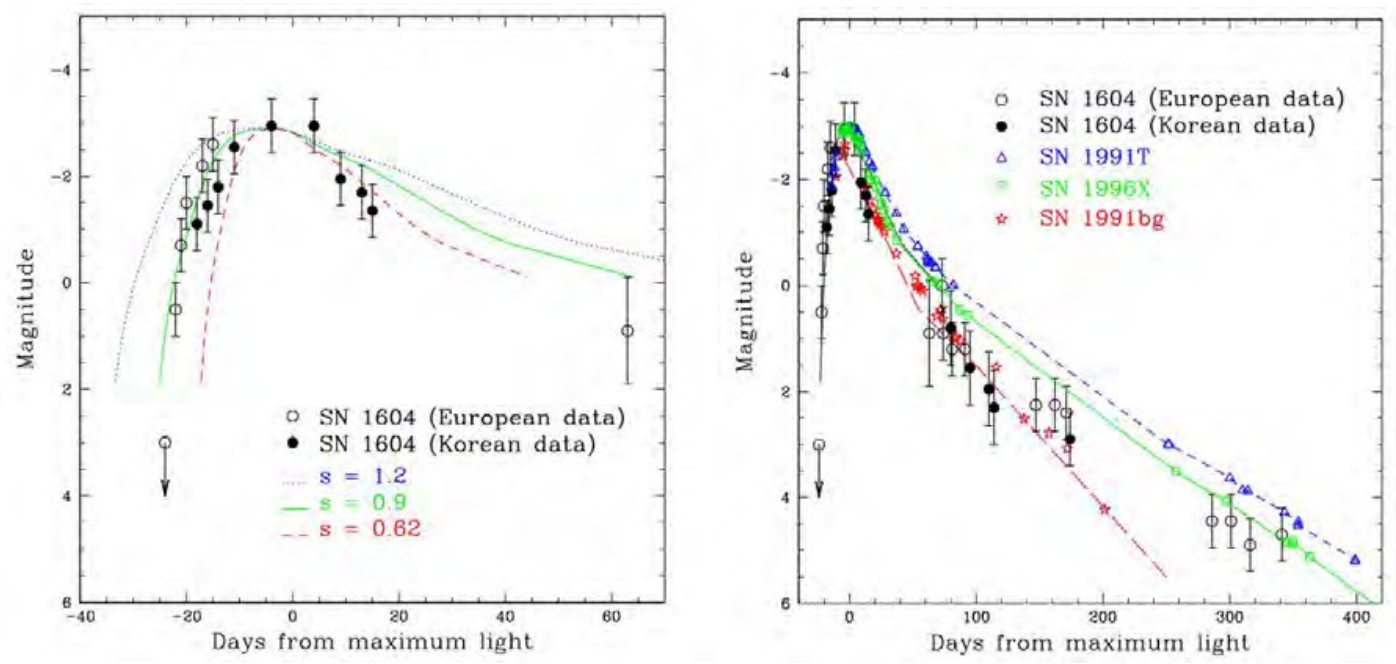

Figure 7: Light curve of SN1604. Left: Around the peak of brightness. Right: Within and over 100 days from the maximum. From [17].

The supernova remnant has an angular radius of 2 arcmin, which corresponds to an estimated radius, given the distance, of about 10 light years.

\section{New observations and physical implications}

Reviews of recent data are in $[19,16]$. 
More recently the the High Energy Stereoscopic System (H.E.S.S.) reported strong evidence for agammaray signal betewwn $225 \mathrm{GeV}$ and $10 \mathrm{TeV}$ based on deep observations of with an exposure of 152 hours [13]. The signal matches the signal between $1 \mathrm{GeV}$ and $100 \mathrm{GeV}$ by a tentative source positionally consistent with the remnant extracted from the data from the Fermi-LAT gamma-ray satellite.

The gamma-ray emission is likely of hadronic origin, thus supporting the conjecture that Kepler's supernova remnant is a site of acceleration of cosmic rays.

\section{Acknowledgements}

We thank Eugenio Bottacini and Alessia Spolon for help and useful discussions.

\section{References}

[1] Le Opere di Galileo Galilei, Edizione Nazionale, Antonio Favaro ed., vol. I-XX, Barbera, Firenze 1890-1909. Shortly called Opere.

[2] W. Baade, "Nova Ophiuchi of 1604 as a supernova", The Astrophysical Journal 97 (1943) 119

[3] W.P. Blair, “Kepler's Supernova Remnant: The View at 400 Years”, arXiv preprint astro-ph/0410081 (2004)

[4] T. Brahe, De nova stella, anni 1572, Copenhagen 1573

[5] B. Capra, Consideratione astronomica circa la nova, e portentosa stella che nel'anno 1604 al dì 10 Ottobre apparse, con un breve giudicio delli suoi significati, Padua 1605, in Opere, Vol.II

[6] A. De Angelis and M. Pimenta, Introduction to particle and astroparticle physics, Springer Nature, Heidelberg 2018

[7] A. De Angelis, I diciott'anni migliori della mia vita, Castelvecchi 2021

[8] A. Favaro, Opere, Vol. II

[9] A. Favaro, Opere, Vol. X

[10] A. Favaro, Galileo Galilei e lo studio di Padova, Antenore, Padova 1966

[11] G. Galilei, Dialogue of Cecco di Ronchitti da Bruzene, Padua 1605

[12] G. Galilei, Difesa contro alle calunnie et imposture di Baldessar Capra, Padua 1607, in Opere, Vol.II

[13] H.E.S.S. Collaboration, “Deep observations of Kepler's SNR with H.E.S.S”, arXiv:2107.11582

[14] J. Kepler. De Stella Nova in pede serpentarii, et qui sub eius exortum de novo iniit, Trigono igneo, Prag 1606

[15] A. Lorenzini, Discorso intomo alla nuova stella, Padua 1605

[16] S.P. Reynolds et al., "A Deep Chandra Observation of Kepler's Supernova Remnant: A Type Ia Event with Circumstellar Interaction". The Astrophysical Journal 668 (2007) L135

[17] P. Ruiz-Lapuente, "The light curve and distance of the Kepler supernova: News from four centuries ago", The Astrophysical Journal 842 (2017) 112

[18] W. Shea, "Galileo and the Supernova of 1604", in 1604-2004: Supernovae as Cosmological Lighthouses, 2005, p. 13

[19] J. Vink, "Supernova 1604, Kepler's Supernova, and its Remnant” in A.W. Alsabti, P. Murdin (eds.), Handbook of Supernovae, Springer Nature, Heidelberg 2017

[20] Z.R. Wang et al., "SN1604 in the East", in 1604-2004: Supernovae as Cosmological Lighthouses, Vol. 342. 2005 , p. 48 